\title{
Multi-Battle n-Player Dynamic Contests
}

Citation for published version (APA):

Anbarci, N., Cingiz, K., \& Ismail, M. (2018). Multi-Battle n-Player Dynamic Contests. Maastricht University, Graduate School of Business and Economics. GSBE Research Memoranda No. 003 https://doi.org/10.26481/umagsb.2018003

Document status and date:

Published: 08/02/2018

DOI:

10.26481/umagsb.2018003

Document Version:

Publisher's PDF, also known as Version of record

\section{Please check the document version of this publication:}

- A submitted manuscript is the version of the article upon submission and before peer-review. There can be important differences between the submitted version and the official published version of record.

People interested in the research are advised to contact the author for the final version of the publication, or visit the DOI to the publisher's website.

- The final author version and the galley proof are versions of the publication after peer review.

- The final published version features the final layout of the paper including the volume, issue and page numbers.

Link to publication

\footnotetext{
General rights rights.

- You may freely distribute the URL identifying the publication in the public portal. please follow below link for the End User Agreement:

www.umlib.nl/taverne-license

Take down policy

If you believe that this document breaches copyright please contact us at:

repository@maastrichtuniversity.nl

providing details and we will investigate your claim.
}

Copyright and moral rights for the publications made accessible in the public portal are retained by the authors and/or other copyright owners and it is a condition of accessing publications that users recognise and abide by the legal requirements associated with these

- Users may download and print one copy of any publication from the public portal for the purpose of private study or research.

- You may not further distribute the material or use it for any profit-making activity or commercial gain

If the publication is distributed under the terms of Article $25 \mathrm{fa}$ of the Dutch Copyright Act, indicated by the "Taverne" license above, 


\section{Maastricht University}

Nejat Anbarci, Kutay Cingiz, Mehmet S. Ismail

Multi-Battle n-Player Dynamic Contests

$\mathrm{RM} / 18 / 003$

\section{GSBE}

Maastricht University School of Business and Economics

Graduate School of Business and Economics

P.O Box 616

NL- 6200 MD Maastricht

The Netherlands 


\title{
Multi-Battle $n$-Player Dynamic Contests*
}

\author{
Nejat Anbarci ${ }^{\dagger} \quad$ Kutay Cingiz ${ }^{\ddagger} \quad$ Mehmet S. Ismail ${ }^{\S}$
}

January 31, 2018

\begin{abstract}
In presidential primaries, proportional campaign resource allocation to states with respect to their delegate numbers is a desirable concept. To study proportionality, we introduce a novel model for $n$-player multi-battle dynamic contests. We show that when players maximize their expected number of delegates there is a subgame perfect equilibrium in which players allocate their resources proportionally. However for at least 4 number of states and at least 2 delegates, when players maximize their probability of winning, there is always a distribution of delegates over the states such that population proportionality is not satisfied.

Keywords: Presidential elections; presidential primaries; population proportionality; multi-battle contests; dynamic contests

JEL Classification Numbers: C73, D72
\end{abstract}

${ }^{*}$ We are grateful to Jean-Jacques Herings, Arkadi Predtetchinski, and János Flesch without whose feedbacks it would not be possible to complete this paper. We would like to thank Steven Brams, Christian Seel and Cédric Wasser for their valuable comments and suggestions.

${ }^{\dagger}$ Department of Economics, Deakin University, 70 Elgar Road, Burwood, VIC 3125, Australia. nejat.anbarci@deakin.edu.au

${ }_{\ddagger}^{\ddagger}$ Department of Economics, Maastricht University, P.O. Box 616, 6200 MD, Maastricht, The Netherlands. K.Cingiz@maastrichtuniversity.nl

${ }^{\S}$ Department of Political Economy, King's College London, London, WC2R 2LS, UK. mehmet.s.ismail@gmail.com 


\section{Introduction}

Many contests consist of multiple battles, where the final success or failure is determined by the outcome of these battles. For instance, to win a singles tennis match a player needs to win two or three sets before the opponent does so. ${ }^{1}$ Although sports competitions often constitute the most direct applications of multi-battle contests, such contests have already received considerable attention in other areas such as R\&D races and politics as well. ${ }^{2}$ In politics, the presidential elections provide an example of simultaneous but static (i.e., not dynamic) multi-battle contests, while presidential primaries provide an example of sequential multiple-battle dynamic contests, as for each of the two major political parties (Democrats and Republicans) the candidate who wins the majority of the delegates across all states wins the party's nomination.

Studying a static model of resource allocation in U.S. presidential campaigns in a prominent paper, in which the goal of the candidates is to maximize their expected electoral vote, Brams and Davis (1974) highlighted the concepts of 'population of states' as well as 'population proportionality' in campaign resource allocation. ${ }^{3}$ Brams and Davis (1974, p. 113) concluded that "the winner-take-all feature of the Electoral College-i.e., that the popularvote winner in each state wins all the electoral votes of that state -induces candidates to allocate campaign resources roughly in proportion to the $3 / 2$ 's power of the electoral votes of each state." Moreover, they show that if candidates receive delegates in proportion to their spendings on each state then population proportionality holds.

Later Lake (1979) argued that one would need to assume that the candidates maximize only their probability of winning the election, i.e., one would simply try to receive a majority of electoral votes, instead of complying with Brams and Davis' (1974) assumption that they maximize their expected electoral vote. Nevertheless, Lake's (1979) main result echoes Brams and Davis' (1974) impossibility of population proportionality result in that in Lake's model too it turns out that presidential candidates find it optimal to spend a disproportionately large amount of their funds in the larger states. The main difference between the two models, however, is that Brams and Davis' (1974) model, which assumes that the candidates maximize their expected electoral vote, predicts that candidates allocate campaign resources roughly in proportion to the $3 / 2$ 's power of the electoral votes of each state while Lake's (1979) model, which assumes that the candidates maximize their probability of winning instead, predicts that candidates allocate campaign resources in proportion to the Banzhaf power index of each voter in the electorate. Nevertheless, as

\footnotetext{
${ }^{1}$ In the PGA Tour, which brings professional male golfers together to play in a number of tournaments each year (LPGA does so for female golfers), each tournament consists of multiple battles in that golfers attempt to minimize the total number of shots they take across 72 holes.

${ }^{2}$ Harris and Vickers (1985), for instance, construed a patent race as a multi-battle contest, in which two players alternate in expending resources in a sequence of single battles. These battles or sub-contests serve as the components of the overall $\mathrm{R} \& \mathrm{D}$ contest.

Just like in a singles tennis match, the player who is first to win a given number of battles wins the contest, by obtaining the patent.

${ }^{3}$ As noted by Brams and Davis (1973), the population of a state need not exactly reflect the proportion of the voting-age population who are registered and actually vote in a presidential election. Following Brams and Davis (1973), we too have taken the simplest course of using population as a first-approximation estimate of the proportion of voters.
} 


\begin{tabular}{|l|l|}
\hline Win probability maximization & Expected delegate maximization \\
\hline $\begin{array}{l}\text { Population proportionality } \\
\text { does not hold (Theorem 1) }\end{array}$ & Population proportionality \\
holds (Theorem 2)
\end{tabular}

Table 1: A summary of our results

noted by Lake (1979, p. 130), "the Banzhaf and 3/2's rules give virtually the same results."

Sela and Erez (2013) study a two player dynamic Tullock contest. Each player maximizes the sum of the expected payoffs (similar to expected delegate maximization in our setting) for all districts. They provide a subgame prefect equilibrium such that if the winning value (number of delegates) is equal between the stages and for each resource unit that a player allocates, he loses $0 \leq \alpha \leq 1$ units of resource from his budget, then the players' resource allocations are weakly decreasing over the stages. Duffy and Matros (2015) study static contests with two players with asymmetric yet similar budgets - generalizing Lake's (1979) paper; they provide the Nash equilibrium in contests with up to four states. In a similar setting, Deck, Sarangi, and Wiser (2017) study symmetric static contests with two players. Under the assumption that players do not have budget constraints, they find the Nash equilibrium of the symmetric game (Electoral College). ${ }^{4}$

While voting occurs simultaneously in U.S. presidential elections, individuals vote sequentially in U.S. presidential primaries leading to the presidential elections, which consists of a series of elections - primaries - held across many states with different population sizes over several months.

This paper asks the following question: Does one always have the impossibility of population proportionality in campaign resource allocation in the sequential multi-battle $n$-player dynamic-contest environment of presidential primaries? We show that when players maximize their expected number of delegates (just like Brams and Davis, 1973, have assumed) there is a subgame perfect equilibrium in which players allocate their resources proportionally. However, when players maximize their probability of winning (just like Lake, 1979, has assumed), proportionality may not be satisfied.

The paper is organized as follows. In Section 2, we introduce a novel model for $n$ player multi-battle dynamic contests. In Section 3, we analyze the dynamic contests in which players maximize their probability of winning. We provide two examples with three and four states. In Section 4, we show that population proportionality satisfies in dynamic contests whenever players maximize their expected number of delegates.

\section{$2 \quad$ Model}

We consider dynamic contests where there are $m$ states (battle fields), indexed by $t=$ $1,2, \ldots, m$, and $n$ players, indexed by $i=1,2, \ldots, n$. The battles take place in a predetermined sequential order in states (e.g., New York, California, etc.). Each player $i$ has a fixed

\footnotetext{
${ }^{4}$ Additional works on dynamic resource allocation contests include the followings. Dziubinski, Goyal and Minarsch (2017) study multi-battle dynamic contests on networks in which neighboring 'kingdoms' battle in a sequential order. In a two-player and two-stage campaign resource allocation game Kovenock and Roberson (2009) characterize the unique subgame perfect equilibrium.
} 
budget $W_{i}$ that he can allocate over the states. In each state $t$, the number of delegates that can be won is denoted by $x^{t}$. Each time period $t$, the battle at state $t$ takes place and each player $i$ simultaneously chooses a pure action (allocation) denoted by $w_{i}^{t}$ which is smaller than or equal to the budget, $W_{i}$, minus the already spent allocation by player $i$ till state $t$. Given the chosen actions in state $t, w^{t}:=\left(w_{1}^{t}, \ldots, w_{n}^{t}\right)$, the probability of player $i$ winning all delegates of state $t$ is defined by a contest success function

$$
p_{i}^{t}\left(w^{t}\right)= \begin{cases}\frac{w_{i}^{t}}{\sum_{j} w_{j}^{t}} & \text { if } \sum_{j} w_{j}^{t}>0 \\ \frac{1}{n} & \text { if } \sum_{j} w_{j}^{t}=0 .\end{cases}
$$

Thus, a dynamic contest is a constant sum game, as what a player wins is a loss for the other players. To avoid trivial cases, we assume that for any $t, x^{t}<\sum_{t^{\prime} \neq t} x^{t^{\prime}}$, that is, there is no "dictatorial state." Let $x_{i}^{t}$ be the number of delegates player $i$ wins at state $t$, which is $x^{t}$ with probability $p_{i}^{t}\left(w^{t}\right)$ and 0 with probability $1-p_{i}^{t}\left(w^{t}\right)$.

The set of histories of length $t$ is denoted by $H^{t}$. A history of length $t \geq 1$ is a sequence

$$
h^{t}:=\left(\left(\left(w_{1}^{1}, x_{1}^{1}\right), \ldots,\left(w_{n}^{1}, x_{n}^{1}\right)\right), \ldots,\left(\left(w_{1}^{t}, x_{1}^{t}\right), \ldots,\left(w_{n}^{t}, x_{n}^{t}\right)\right)\right)
$$

satisfying the following conditions

(i) For each $1 \leq i \leq n$ and for each $1 \leq t^{\prime} \leq t, w_{i}^{t^{\prime}} \in\left[0, W_{i}-\sum_{j<t^{\prime}} w_{i}^{j}\right]$.

(ii) For each state $t^{\prime} \leq t$, there exists a unique player $i$ such that $x_{i}^{t^{\prime}}=x^{t^{\prime}}$ and for all $j \neq i, x_{j}^{t^{\prime}}=0$.

The first property states that each action at any given state $t$ is bounded by the budget set which diminishes after each action taken in previous battles. The second property states that the winner of a battle gets all the delegates in that state (winner-takes-all). The history $H^{0}$ consists of only the empty sequence $\varnothing$. Let $H=H^{0} \cup H^{1} \cup \ldots \cup H^{m}$. Note that, the history $h^{t-1}$ is presented to all players at time $t$. There is a subset $\overline{H^{t}} \subset H$ consisting of histories of length $t$ where the game comes to an end at state $t$. We call $\overline{H^{t}}$ the set of terminal histories of length $t$. If the game has not ended before state $m$ then the game ends at state $m$. We will specify terminal histories in detail later on.

The remaining budget of player $i$ after history $h^{t} \in H$ is defined as $B_{i}\left(h^{t}\right)=W_{i}-$ $\sum_{j \leq t} w_{i}^{j}$ where for every $j \leq t, w_{i}^{j}$ is a realized spending of history $h^{t}$. The realized winning schedule of a given history $h^{t} \in H$, denoted by $V\left(h^{t}\right)$, is the sequence of players that won the battles at states $1, \ldots, t$. Thus $V\left(h^{t}\right) \in\{1, \ldots, n\}^{t}$. For example, if $h^{3}=\left(\left(\left(w_{1}^{1}, x_{1}^{1}\right),\left(w_{2}^{1}, 0\right)\right),\left(\left(w_{1}^{2}, 0\right),\left(w_{2}^{2}, x_{2}^{2}\right)\right),\left(\left(w_{1}^{3}, 0\right),\left(w_{2}^{3}, x_{2}^{3}\right)\right)\right)$ in a two-player dynamic contest with $m>3$, then $V\left(h^{3}\right)=(1,2,2)$.

For player $i$, a pure strategy $\sigma_{i}$ is a sequence of $\sigma_{i}^{t}$ 's such that for each $t, \sigma_{i}^{t}$ assigns, to every $h^{t-1} \in H^{t-1}$, allocation $\sigma_{i}^{t}\left(h^{t-1}\right) \in\left[0, B_{i}\left(h^{t-1}\right)\right]$. A pure strategy profile is denoted by $\sigma=\left(\sigma_{i}\right)_{i \leq n}$. The set of pure strategies of player $i \leq n$ is denoted by $\Sigma_{i}$ and the set of pure strategy profiles by $\Sigma=\times_{i \leq n} \Sigma_{i}$. For any $\sigma \in \Sigma$, let $(\sigma \mid h)=\left(\left(\sigma_{1} \mid h\right), \ldots,\left(\sigma_{n} \mid h\right)\right)$ denote the strategy profile induced by $\sigma$ in the subgame starting from history $h$.

Throughout the paper, we will analyze two different dynamic contests in which the players either (i) maximize the probability of winning the contest, or (ii) maximize the 
expected number of delegates.

Maximizing probability of winning: A player wins the dynamic contest if he or she receives the plurality of delegates. In this part, we assume that players maximize the probability of winning. If at some history a player is guaranteed to lose, then the player's remaining budget after that history is 0 . Thus players who guaranteed to lose stay in the game and proportionally spend 0 at the remaining states. Furthermore, if at some history a player is already guaranteed to win, then the contest ends at this history. Accordingly, an element $\bar{h}^{t} \in H$ is called terminal if the contest ends with battle at state $t$-if either $t=m$ or there exists a player $i$ such that

$$
\sum_{j \leq t} x_{i}^{j}>\max \left\{\sum_{j \leq t} x_{i^{\prime}}^{j} \mid i^{\prime} \neq i\right\}+x^{t+1}+\ldots+x^{m} .
$$

Let $\bar{H}=\bigcup_{t<m} \overline{H^{t}}$ be the set of all terminal histories. For any given $\bar{h}^{t} \in \bar{H}$, let $C\left(\bar{h}^{t}\right)$ be the set of players that have won the highest number of delegates up to and including state $t$, which is defined by $C\left(\bar{h}^{t}\right)=\arg \max _{i \leq n} \sum_{j \leq t} x_{i}^{j}$. For $\bar{h}^{t} \in \bar{H}$, player $i$ receives a payoff equal to

$$
u_{i}\left(\bar{h}^{t}\right)= \begin{cases}\frac{1}{\left|C\left(\bar{h}^{t}\right)\right|} & \text { if } i \in C\left(\bar{h}^{t}\right) \\ 0 & \text { otherwise. }\end{cases}
$$

For every $t \leq m$, we define $\rho: \Sigma \times H^{t} \rightarrow \mathcal{P}(\bar{H})$ where $\mathcal{P}(\bar{H})$ is the power set of $\bar{H}$ such that $\rho\left(\sigma \mid h^{t}\right)$ denotes the set of terminal histories that are reached with positive probability with respect to $\sigma$ conditional on reaching history $h^{t} \in H^{t}$. The probability of a terminal history $\bar{h}$ being reached with respect to $\sigma$ conditional on reaching $h^{t}$ is denoted as $q\left(\sigma, \bar{h} \mid h^{t}\right)$. The payoff for player $i \leq n$ induced by a pure strategy profile $\sigma \in \Sigma$ at any history $h^{t} \in H^{t}$ is defined as

$$
v_{i}\left(\sigma \mid h^{t}\right)=\sum_{\bar{h} \in \rho\left(\sigma \mid h^{t}\right)} q\left(\sigma, \bar{h} \mid h^{t}\right) u_{i}(\bar{h})
$$

We denote $v_{i}(\sigma \mid \varnothing)$ by $v_{i}(\sigma)$. Equation (2.5) and $q\left(\sigma, \bar{h} \mid h^{t}\right)$ define the payoff of each player $i$ as follows. For any given terminal history $\bar{h}$ in $\rho\left(\sigma \mid h^{t}\right)$, we multiply the probability of reaching the given history $\bar{h}$ with the utility player $i$ gets at terminal history $\bar{h}$ and then we sum over all terminal histories in $\rho\left(\sigma \mid h^{t}\right)$.

Maximizing number of delegates: Now suppose that players maximize the number of delegates they collect, so the terminal histories are exactly the histories with length $m$. The set of terminal histories is denoted by $\overline{H^{m}}$, which is equal to $H^{m}$. For any $\bar{h}^{m} \in \overline{H^{m}}$, player $i$ receives a payoff equal to

$$
\bar{u}_{i}\left(\bar{h}^{m}\right)=\sum_{t \leq m} x_{i}^{t}
$$

where $\bar{h}^{m}:=\left(\left(\left(w_{1}^{1}, x_{1}^{1}\right), \ldots,\left(w_{n}^{1}, x_{n}^{1}\right)\right), \ldots,\left(\left(w_{1}^{m}, x_{1}^{m}\right), \ldots,\left(w_{n}^{m}, x_{n}^{m}\right)\right)\right)$. 
Analogous to the maximizing probability of winning case, the set of terminal histories induced by a strategy profile $\sigma$ conditional on reaching history $h$ is denoted by $\rho(\sigma \mid h)$, which is a subset of $\overline{H^{m}}$. The payoff for player $i \leq n$ induced by a pure strategy profile $\sigma \in \Sigma$ at any $h^{t} \in H^{t}$ is

$$
v_{i}\left(\sigma \mid h^{t}\right)=\sum_{\bar{h}^{m} \in \rho\left(\sigma \mid h^{t}\right)} q\left(\sigma, \bar{h}^{m} \mid h^{t}\right) \bar{u}_{i}\left(\bar{h}^{m}\right) .
$$

Subgame perfect equilibrium: A pure strategy profile $\sigma \in \Sigma$ is a subgame perfect equilibrium if for every state $t \leq m$, for every history $h \in H^{t}$, for every player $i \leq n$, and for every strategy $\sigma_{i}^{\prime} \in \Sigma_{i}$

$$
v_{i}(\sigma \mid h) \geq v_{i}\left(\sigma_{-i}, \sigma_{i}^{\prime} \mid h\right) .
$$

A strategy profile $\sigma \in \Sigma$ is a subgame perfect equilibrium if and only if for every $h \in H, \sigma$ induces an equilibrium in the subgame starting with history $h$.

Proportional strategy profile: Here we define a very specific pure strategy profile $\sigma$. For any $t$, for any nonterminal history $h^{t-1} \in H-\bar{H}$, and for any player $i$, let

$$
\sigma_{i}^{t}\left(h^{t-1}\right)=B_{i}\left(h^{t-1}\right) \frac{x^{t}}{x^{t}+\ldots+x^{m}} .
$$

We call $\sigma$ the proportional pure strategy profile. Note that under $\sigma$, no matter what the other players do, every player proportionally allocates his available budget over the remaining states.

A dynamic contest is called population proportional if the proportional strategy profile is a subgame perfect equilibrium. The focus of the paper is the class of dynamic contests which are population proportional.

\section{Maximizing the probability of winning}

In this section, the players maximize their probability of winning the primary electionsjust like Lake (1979) has assumed. Here we analyze three examples of dynamic contests: i) 3-identical-state dynamic contest. ii) 4-state dynamic contest where the first state is larger (higher delegate number) than the 3 other identical states. iii) 4-state dynamic contest where the last state is larger (higher delegate number) than the first 3 identical states. We show that 3-identical-state dynamic contest satisfies population proportionality. Furthermore, we provide nontrivial examples of 4-state battles that do not admit population proportionality. The 3-state example consists of 1-delegate states while the 4-state examples involve three 1-delegate states and one 2-delegate state with two different possible spots in the sequence of battles.

Finally, we show that for any $n$-player dynamic contest with at least four states and at least two delegates, there is always a distribution of delegates over the states such that population proportionality does not satisfy. This result too echoes Brams and Davis' (1974) and Lake's (1979) result on impossibility of population proportionality. We prove an extension of this result to dynamic contests. 


\subsection{Example I: The dynamic contest with 3 identical states}

Suppose that there are two players $A$ and $B$ with equal budget $W=100$ and three identical states. We use backward induction. If for given $h^{2}, V\left(h^{2}\right)$ is equal to $(A, A)$ or $(B, B)$, which means player $A$ has already won or lost the first two battles, then the contest comes to an end and player $A$ wins or loses, respectively. If for given $h^{2}, V\left(h^{2}\right)$ is equal to $(A, B)$ or $(B, A)$ then the dynamic contest continues to the last battle and in the subgame after $h^{2}$, the unique best response is to allocate all of the remaining budget to the last battle. Therefore, in any subgame after any nonterminal history $h^{2}$ the strategy profile $\left(\sigma_{A}^{3}, \sigma_{B}^{3}\right)$, which is to spend the remaining budget to the last state, is the unique Nash equilibrium.

Now, suppose that for $h^{1}, V\left(h^{1}\right)=(A)$. Then, player $A$ 's best response to $B$ is to maximize his payoff

$$
v_{A}\left(\sigma \mid h^{1}\right)=v_{A}\left(\left(\left(\sigma_{A}^{1}, \sigma_{B}^{1}\right),\left(\sigma_{A}^{2}, \sigma_{B}^{2}\right),\left(\sigma_{A}^{3}, \sigma_{B}^{3}\right)\right) \mid h^{1}\right)
$$

with respect to $\sigma_{A}^{2}$. Given a fixed $\sigma_{B}^{2}$, player $A$ solves the following maximization problem

$$
\begin{aligned}
& \max _{\sigma_{A}^{2}} v_{A}\left(\sigma \mid h^{1}\right)=\max _{\sigma_{A}^{2}\left(h^{1}\right)}( p_{A}^{2}\left(\sigma_{A}^{2}\left(h^{1}\right), \sigma_{B}^{2}\left(h^{1}\right)\right) \\
&+\left(1-p_{A}^{2}\left(\sigma_{A}^{2}\left(h^{1}\right), \sigma_{B}^{2}\left(h^{1}\right)\right)\right) \\
&\left.\times p_{A}^{3}\left(B_{A}\left(h^{1}\right)-\sigma_{A}^{2}\left(h^{1}\right), B_{B}\left(h^{1}\right)-\sigma_{B}^{2}\left(h^{1}\right)\right)\right) \\
&=\max _{\sigma_{A}^{2}\left(h^{1}\right)}( \frac{\sigma_{A}^{2}\left(h^{1}\right)}{\sigma_{A}^{2}\left(h^{1}\right)+\sigma_{B}^{2}\left(h^{1}\right)}+\frac{\sigma_{B}^{2}\left(h^{1}\right)}{\sigma_{A}^{2}\left(h^{1}\right)+\sigma_{A}^{2}\left(h^{1}\right)} \\
&\left.\quad \times \frac{100-w_{A}^{1}-\sigma_{A}^{2}\left(h^{1}\right)}{200-w_{A}^{1}-\sigma_{A}^{2}\left(h^{1}\right)-w_{B}^{1}-\sigma_{B}^{2}\left(h^{1}\right)}\right) \\
&=\max _{w_{A}^{2}}\left(\frac{w_{A}^{2}}{w_{B}^{2}+w_{B}^{2}}+\frac{w_{B}^{2}}{w_{A}^{2}+w_{B}^{2}}\right. \\
&\left.\quad \times \frac{100-w_{A}^{1}-w_{A}^{2}}{200-w_{A}^{1}-w_{A}^{2}-w_{B}^{1}-w_{B}^{2}}\right) .
\end{aligned}
$$

Equality (3.2) holds, since player $A$ already won the first state, in order to win the contest player $A$ either needs to win the second battle - given $\bar{h}^{2}$ with $V\left(\bar{h}^{2}\right)=(A, A)$-, or if he loses the second then to win the third battle - given $h^{2}$ with $V\left(h^{2}\right)=(A, B)$. Moreover, if the game continues to the last state, then spending the remaining budget is the unique best reponse in the subgame after given history. Equality (3.3) follows from the contest success function. Equality (3.4) follows from the definition of a strategy which maps histories to actions in the following battle.

As player $A$ wants to maximize $v_{A}\left(\sigma \mid h^{1}\right)$, player $B$ wants to minimize it. We derive best response functions from the first-order condition of $v_{A}\left(\sigma \mid h^{1}\right)$ with respect to $\sigma_{A}^{2}\left(h^{1}\right)$ and $\sigma_{B}^{2}\left(h^{1}\right)$, respectively. The intersection of best responses provides us the following two conditions $^{5}$

$$
\begin{aligned}
& w_{A}^{2}=\frac{1}{2}\left(100-w_{A}^{1}\right), \\
& w_{B}^{2}=\frac{1}{2}\left(100-w_{B}^{1}\right) .
\end{aligned}
$$

\footnotetext{
${ }^{5}$ Detailed calculations are available in the Appendix.
} 
So far, we have showed that the pair $\left(\sigma_{A}^{3}, \sigma_{B}^{3}\right)$-in which players each allocate the remaining budget to the last state-, and the pair $\left(\left(\sigma_{A}^{2}, \sigma_{B}^{2}\right),\left(\sigma_{A}^{3}, \sigma_{B}^{3}\right)\right)$-in which strategies satisfy (3.5) and (3.6) - are Nash equilibria in their respective subgames. Now, we suppose that $h=\varnothing$. Then, player $A$ best responds to $B$ by maximizing his payoff $v_{A}(\sigma \mid \varnothing)=v_{A}(\sigma)$ with respect to $\sigma_{A}^{1}(\varnothing)$

$$
\begin{gathered}
\max _{\sigma_{A}^{1}(\varnothing)} v_{A}(\sigma)=\max _{\sigma_{A}^{1}(\varnothing)}\left(p_{A}^{1}\left(w^{1}\right)\left(p_{A}^{2}\left(w^{2}\right)+\left(1-p_{A}^{2}\left(w^{2}\right)\right) p_{A}^{3}\left(w^{3}\right)\right)\right. \\
\left.+\left(1-p_{A}^{1}\left(w^{1}\right)\right) p_{A}^{2}\left(w^{2}\right) p_{A}^{3}\left(w^{3}\right)\right)
\end{gathered}
$$

where $w^{1}=\left(\sigma_{A}(\varnothing), \sigma_{B}(\varnothing)\right)$, and $w^{2}, w^{3}$ are elements of $\left[0,100-w_{A}^{1}\right] \times\left[0,100-w_{B}^{1}\right]$ and $\left[0,100-w_{A}^{1}-w_{A}^{2}\right] \times\left[0,100-w_{B}^{1}-w_{B}^{2}\right]$, respectively. But since we have already concluded that whoever wins the first battle, both players should invest equally all their remaining budget to the last two states by equations (3.5) and (3.6), we can write $w_{A}^{2}=w_{A}^{3}=(1 / 2)\left(100-w_{A}^{1}\right)$ and $w_{B}^{2}=w_{B}^{3}=(1 / 2)\left(100-w_{B}^{1}\right)$. Thus, we can rewrite equation (3.7) as

$$
\max _{\sigma_{A}(\varnothing)=w_{A}^{1}} \frac{\left(w_{A}^{1}-100\right)\left(\left(w_{A}^{1}\right)^{2}+3\left(w_{A}^{1}\right)\left(w_{B}^{1}-100\right)-100 w_{B}^{1}\right)}{\left(w_{A}^{1}+w_{B}^{1}-200\right)^{2}\left(w_{A}^{1}+w_{B}^{1}\right)} .
$$

Equations (3.7) and (3.8) follows from the analogous reasoning for equations (3.2),(3.3) and (3.4). By the same method as for $v_{A}\left(\sigma \mid h^{1}\right)$, the first order condition of $v_{A}(\sigma)$ with respect to $\sigma_{A}(\varnothing)$ and $\sigma_{B}(\varnothing)$ yields the best response functions of players $A$ and $B$. The intersection of the best responses leads to the condition $w_{A}^{1}=w_{B}^{1}=100 / 3$. From equations (3.5), (3.6) and $w_{A}^{1}=w_{B}^{1}=100 / 3$, we deduce that $w_{A}^{1}=w_{A}^{2}=w_{A}^{3}=w_{B}^{1}=w_{B}^{2}=w_{B}^{3}=100 / 3$, which concludes that every subgame perfect equilibrium strategy profile of Example I satisfies proportionality. ${ }^{6}$

\subsection{Example II: Dynamic contests with 4 states}

To illustrate our model with a nontrivial example, suppose that there are two players $A$ and $B$ with equal budget $W=100$ and 4 states, one of which is a 2-delegate state and the other states each has 1 delegate. Thus, if a player wins the 2-delegate state and one other state, or wins all the 1-delegate states, then he ends up winning the dynamic contest. We next provide two examples for 4-state case in which the 2-delegate state is the first and last battle, respectively. We show that neither contest admits a proportional subgame perfect equilibrium strategy profile. ${ }^{7}$

Case $\mathbf{I}^{8}$ : Let the 2-delegate state be the first battle. If for given $h^{2}, V\left(h^{2}\right)$ is equal to $(A, A)$ or $(B, B)$, which means player $A$ has already won or lost the first two battles, then the contest comes to an end and player $A$ wins or loses, respectively. If for given $h^{3}, V\left(h^{3}\right)$ is equal to $(A, B, B)$ or $(B, A, A)$, then the dynamic contest continues to the last battle. And, for the subgame after the given history the unique best response for each player $\left(\sigma_{A}^{4}\right.$ and $\left.\sigma_{B}^{4}\right)$ is to allocate all the remaining budget to the last battle.

\footnotetext{
${ }^{6}$ This example is similar to the benchmark example of $\mathrm{Fu}, \mathrm{Lu}$, and Pan (2015, p. 9); though, our settings differ when the states are not identical.

${ }^{7}$ Calculations are available upon request.

${ }^{8}$ From this point on, we take $p_{i}^{t}$ as $p_{i}^{t}\left(w^{t}\right)$.
} 
For given $h^{2}, V\left(h^{2}\right)=(A, B)$, player $A$ best responds to $B$ by maximizing his payoff $v_{A}\left(\sigma \mid h^{2}\right)$ with respect to $\sigma_{A}^{3}$

$$
\max _{\sigma_{A}^{3}} v_{A}\left(\sigma \mid h^{2}\right)=\max _{\sigma_{A}^{3}\left(h^{2}\right)} v_{A}\left(\sigma \mid h^{2}\right)=\max _{w_{A}^{3}}\left(p_{A}^{3}+\left(1-p_{A}^{3}\right) p_{A}^{4}\right)
$$

which is analogous to the dynamic contest with 3 identical states. Hence, each player allocating equally his remaining budget to states 3 and 4 is the unique best response, $\left(\sigma_{A}^{3}, \sigma_{A}^{4}\right)$ and $\left(\sigma_{B}^{3}, \sigma_{B}^{4}\right)$, for subgames starting with history $h^{2}$. Now suppose that for given $h^{1}$, if $V\left(h^{1}\right)=(A)$, then player $A$ best responds to $B$ by maximizing his payoff

$$
\max _{\sigma_{A}^{2}\left(h^{1}\right)} v_{A}\left(\sigma \mid h^{1}\right)=\max _{w_{A}^{2}}\left(p_{A}^{2}+\left(1-p_{A}^{2}\right) p_{A}^{3}+\left(1-p_{A}^{2}\right)\left(1-p_{A}^{3}\right) p_{A}^{4}\right)
$$

We derive Equation (3.9) by an analogous method from Example I. To obtain the best response functions, we take the first order conditions of the payoff functions with respect to $\sigma_{A}^{2}\left(h^{1}\right)$ and $\sigma_{B}^{2}\left(h^{1}\right)$, respectively. The intersection of the best responses yields the following two conditions

$$
\begin{aligned}
& w_{A}^{2}=\frac{1}{3}\left(100-w_{A}^{1}\right), \\
& w_{B}^{2}=\frac{1}{3}\left(100-w_{B}^{1}\right) .
\end{aligned}
$$

Given that each player wins one battle from the first two battles, we already concluded that players allocate their remaining budget to states 3 and 4 equally. Thus, by equations (3.10) and (3.11), we conclude that whoever is the winner of the first battle, players allocating equally their remaining budget to three identical states is the best response for any subgame after the first battle.

Now, we suppose that $h^{1}=\varnothing$. Then, player $A$ best responds to $B$ by maximizing his payoff $v_{A}(\sigma \mid \varnothing)=v_{A}(\sigma)$ with respect to $\sigma_{A}^{1}(\varnothing)$ which is $\max _{\sigma_{A}^{1}(\varnothing)} v_{A}(\sigma)$, i.e.,

$$
\begin{aligned}
& \max _{\sigma_{A}^{1}(\varnothing)} v_{A}(\sigma)= \max _{w_{A}^{1}}\left(p _ { A } ^ { 1 } \left(p_{A}^{2}+\left(1-p_{A}^{2}\right) p_{A}^{3}\right.\right. \\
&\left.\left.+\left(1-p_{A}^{2}\right)\left(1-p_{A}^{3}\right) p_{A}^{4}\right)+\left(1-p_{A}^{1}\right) p_{A}^{2} p_{A}^{3} p_{A}^{4}\right) \\
&= \\
& \\
&+\frac{\left(w_{A}^{1}-100\right)\left(4\left(w_{A}^{1}\right)^{2}\left(w_{B}^{1}-125\right)+\left(w_{A}^{1}\right)^{3}+10000 w_{B}^{1}\right)}{\left(w_{A}^{1}+w_{B}^{1}-200\right)^{3}\left(w_{A}^{1}+w_{B}^{1}\right)} \\
&\left.+w_{A}^{1}-100\right)\left(w_{A}^{1}\left(3\left(w_{B}^{1}\right)^{2}-1100 w_{B}^{1}+70000\right)\right) \\
&\left(w_{A}^{1}+w_{B}^{1}-200\right)^{3}\left(w_{A}^{1}+w_{B}^{1}\right)
\end{aligned}
$$

Equation (3.12) is derived from a similar method applied to equation (3.9). First order condition of equation (3.12) with respect to $w_{A}^{1}$ and $w_{B}^{1}$ yields the best response functions of players $A$ and $B$. We deduce that $w_{A}^{1}=w_{B}^{1}=50$ is at the intersection of the best responses. Hence, equations (3.10) and (3.11) imply that $w_{A}^{2}=w_{A}^{3}=w_{A}^{4}=w_{B}^{2}=w_{B}^{3}=w_{B}^{4}=50 / 3$. In conclusion, there exists a subgame perfect equilibrium strategy profile $\sigma$ such that on an equilibrium path of $\sigma$, players spend half of their budget to the 2-delegate state and then equally split the remaining budget among 1-delegate states. Thus, case I does not admit proportionality. 
Case II: Let the 2-delegate state be the last battle. If for given $h^{2}, V\left(h^{2}\right)$ is equal to $(A, B)$ or $(B, A)$, then players allocating all their remaining budget to the 2-delegate state is the unique best response for the subgame starting from history $h^{2}$. If for given $h^{2}, V\left(h^{2}\right)$ is equal to $(A, A)$, then in the following subgame of the related history, player $A$ needs only one of the remaining states and player $B$ needs both states to win the contest which is the same case as in Example I after the first battle. Thus, the unique best responses are players distributing equally their remaining budget on the last two states. Therefore, in any subgame after any history $h^{2} \in H$, there is no equilibrium that is proportional. Hence, case II does not admit proportionality.

The following theorem provides a class of dynamic contests that does not admit population proportionality whenever players maximize probability of winning.

Theorem 1 For any $m \geq 4$ number of states and any $n \geq 2$ candidates, there exists a dynamic contest, where players maximize their probability of winning, for which population proportionality fails.

Proof: Consider a dynamic contest such that $x^{1}=\ldots=x^{m-1}=1$ and $x^{m}=3$. Consider the history $h^{m-2}$ where candidate 1 wins state 1 , candidate 2 wins state 2 , candidate 1 wins state 3 and so on up to and including state $m-2$. Thus, for history $h^{m-2}$, the maximum amount of delegate difference between candidate 1 and candidate 2 is 1 . In the subgame after history $h^{m-2}$, candidate 1 and candidate 2 spending all their budget to the last state is the unique Nash equilibrium. Since we reach history $h^{m-2}$ with positive probability under the proportional strategy profile, the dynamic contest does not admit population proportionality.

\section{Maximizing the expected number of delegates}

In this section, we assume that players maximize the expected number of delegates - just like Brams and Davis (1973) have assumed. They showed that proportionality is satisfied in two-player static games. The following theorem illustrates a different and intuitive proof for $n$-player dynamic contests.

Theorem 2 For any dynamic contest where players maximize their expected number of delegates, population proportionality is satisfied.

Proof: We show that the proportional strategy profile $\sigma=\left(\sigma_{i}\right)_{i \leq n}$ is robust to oneshot deviations. That is, any player $i$ at any nonterminal history $h^{t}$ can not improve his payoff by changing $\sigma_{i}^{t}$, given that all other players, $j \neq i$, follow the proportional strategy. If player $i$ switches to a strategy $\bar{\sigma}_{i}=\left(\bar{\sigma}_{i}^{t+1}, \sigma_{i}^{t+2}, \ldots, \sigma_{i}^{m}\right)$ after history $h^{t}$ such that $\bar{\sigma}_{i}^{t+1}\left(h^{t}\right) \neq \sigma_{i}^{t+1}\left(h^{t}\right)$, then the expected number of delegates player $i$ wins after state $t$ given the history $h^{t}$ is denoted as $v_{i, t+1}\left(\bar{\sigma}_{i}, \sigma_{-i} \mid h^{t}\right)$, which satisfies

$$
v_{i, t+1}\left(\bar{\sigma}_{i}, \sigma_{-i} \mid h^{t}\right)=\frac{x^{t+1} \bar{\sigma}_{i}^{t+1}\left(h^{t}\right)}{\bar{\sigma}_{i}^{t+1}\left(h^{t}\right)+\sum_{j \neq i} \sigma_{j}^{t+1}\left(h^{t}\right)}+v_{i, t+2}\left(\sigma \mid h_{d e v}^{t+1}\right),
$$


where $h_{d e v}^{t+1}$ is a successor of $h^{t}$ with the property that at state $t+1$ player $i$ spent $\bar{\sigma}_{i}^{t+1}\left(h^{t}\right)$, and each player $j \neq i$ spent proportionally. And the expected number of delegates of player $i$ after history $h^{t}$ if she follows $\sigma$,

$$
v_{i, t+1}\left(\sigma \mid h^{t}\right)=\frac{x^{t+1} \sigma_{i}^{t+1}\left(h^{t}\right)}{\sum_{1 \leq j \leq n} \sigma_{j}^{t+1}\left(h^{t}\right)}+v_{i, t+2}\left(\sigma \mid h^{t+1}\right)
$$

where $h^{t+1}$ is a successor of $h^{t}$ with the property that at state $t+1$, each player spent proportionally. For simplicity we take

$$
\begin{aligned}
& \frac{x^{t+1}+\ldots+x^{m}}{x^{t+1}}=k, \\
& B_{i}\left(h^{t}\right)=a, \\
& \sum_{j \neq i} B_{j}\left(h^{t}\right)=b, \\
& \bar{\sigma}_{i}^{t+1}\left(h^{t}\right)=\sigma_{i}^{t+1}\left(h^{t}\right)+\Delta=\frac{a}{k}+\Delta .
\end{aligned}
$$

where $\Delta$ is a real number. We can rewrite player $i$ 's probability of winning state $t+1$ if he plays $\bar{\sigma}_{i}^{t+1}\left(h^{t}\right)$ as

$$
\frac{\bar{\sigma}_{i}^{t+1}\left(h^{t}\right)}{\bar{\sigma}_{i}^{t+1}\left(h^{t}\right)+\sum_{j \neq i} \sigma_{j}^{t+1}\left(h^{t}\right)}=\frac{\frac{a}{k}+\Delta}{\frac{a}{k}+\Delta+\frac{b}{k}}=\frac{a+\Delta k}{a+\Delta k+b},
$$

and player $i$ 's probability of winning state $t+1$ if he plays $\sigma_{i}^{t+1}\left(h^{t}\right)$ as

$$
\frac{\sigma_{i}^{t+1}\left(h^{t}\right)}{\sum_{1 \leq j \leq n} \sigma_{j}^{t+1}\left(h^{t}\right)}=\frac{\frac{a}{k}}{\frac{a}{k}+\frac{b}{k}}=\frac{a}{a+b} .
$$

Since $\sigma$ is a proportional strategy profile, for any $t$, for any $h^{t}$, and for successor of histories where $h^{t+1}$ is a successor of $h^{t}, h^{t+2}$ is a successor of $h^{t+1}$, and so on up to and including $h^{m}$ is a successor of $h^{m-1}$, given that players follow proportional strategy profile, we have

$$
\frac{\sigma_{i}^{t+1}\left(h^{t}\right)}{\sum_{1 \leq j \leq n} \sigma_{j}^{t+1}\left(h^{t}\right)}=\frac{\sigma_{i}^{t+2}\left(h^{t+1}\right)}{\sum_{1 \leq j \leq n} \sigma_{j}^{t+2}\left(h^{t+1}\right)}=\ldots=\frac{\sigma_{i}^{m}\left(h^{m-1}\right)}{\sum_{1 \leq j \leq n} \sigma_{j}^{m}\left(h^{m-1}\right)}=\frac{a}{a+b},
$$

which means that player $i$ wins each state after $h^{t}$ with equal probability if he/she follows $\sigma_{i}$. That is, if players follow the proportional strategy profile, the proportions of the remaining budgets stay constant throughout the battles. The same property satisfies for the strategy profile $\left(\bar{\sigma}_{i}, \sigma_{-i}\right)$ after history $h_{d e v}^{t+1}$. Hence for successor of histories where $h_{d e v}^{t+2}$ is a successor of $h_{d e v}^{t+1}, h_{d e v}^{t+3}$ is a successor of $h_{d e v}^{t+2}$, and so on up to and including $h_{d e v}^{m}$ is a successor of $h_{d e v}^{m-1}$, given that players follow proportional strategy profile after history $h_{\text {dev }}^{t+1}$, we have

$$
\frac{\sigma_{i}^{t+2}\left(h_{d e v}^{t+1}\right)}{\sum_{1 \leq j \leq n} \sigma_{j}^{t+2}\left(h_{d e v}^{t+1}\right)}=\frac{\sigma_{i}^{t+3}\left(h_{d e v}^{t+2}\right)}{\sum_{1 \leq j \leq n} \sigma_{j}^{t+3}\left(h_{d e v}^{t+2}\right)}=\ldots=\frac{\sigma_{i}^{m}\left(h_{d e v}^{m-1}\right)}{\sum_{1 \leq j \leq n} \sigma_{j}^{m}\left(h_{d e v}^{m-1}\right)} .
$$


Now we can simply calculate player $i$ 's probability of winning any state after history $h_{\text {dev }}^{t+1}$, if player $i$ follows the strategy $\bar{\sigma}_{i}$

$$
\frac{\sigma_{i}^{t+2}\left(h_{d e v}^{t+1}\right)}{\sum_{1 \leq j \leq n} \sigma_{j}^{t+2}\left(h_{d e v}^{t+1}\right)}=\frac{a-\frac{a}{k}-\Delta}{a-\frac{a}{k}-\Delta+b-\frac{b}{k}} .
$$

Therefore we can rewrite equation (4.1) as

$$
v_{i, t+1}\left(\bar{\sigma}_{i}, \sigma_{-i} \mid h^{t}\right)=x^{t+1} \frac{a+\Delta k}{a+\Delta k+b}+\frac{a-\frac{a}{k}-\Delta}{a-\frac{a}{k}-\Delta+b-\frac{b}{k}}\left(x^{t+2}+\ldots+x^{m}\right),
$$

And we can rewrite equation (4.2) as

$$
v_{i, t+1}\left(\sigma \mid h^{t}\right)=\frac{a}{a+b}\left(x^{t+1}+\ldots+x^{m}\right) .
$$

We show that $v_{i}\left(\sigma \mid h^{t}\right)-v_{i}\left(\bar{\sigma}_{i}, \sigma_{-i} \mid h^{t}\right) \geq 0$, in other words show that

$$
x^{t+1}\left(\frac{a}{a+b}-\frac{a+\Delta k}{a+\Delta k+b}\right)+\left(x^{t+2}+\ldots+x^{m}\right)\left(\frac{a}{a+b}-\frac{a-\frac{a}{k}-\Delta}{a-\frac{a}{k}-\Delta+b-\frac{b}{k}}\right) \geq 0 .
$$

Since $k-1=\left(x^{t+2}+\ldots+x^{m}\right) /\left(x^{t+1}\right)$, we can rewrite inequality (4.3) as

$$
\left(\frac{a}{a+b}-\frac{a+\Delta k}{a+\Delta k+b}\right)+(k-1)\left(\frac{a}{a+b}-\frac{a-\frac{a}{k}-\Delta}{a-\frac{a}{k}-\Delta+b-\frac{b}{k}}\right) \geq 0 .
$$

We can simplify inequality (4.4) as

$$
\frac{b \Delta^{2} k^{3}}{(a+b)(a(k-1)+b(k-1)-\Delta k)(a+b+\Delta k)} \geq 0 .
$$

Inequality (4.5) satisfies because we have the following conditions

$$
\begin{aligned}
& a \geq \frac{a}{k}+\Delta, \\
& b(k-1) \geq 0, \\
& \frac{a}{k}+\Delta \geq 0 .
\end{aligned}
$$

Thus, for any $\Delta$ we have $v_{i}\left(\sigma \mid h^{t}\right)-v_{i}\left(\bar{\sigma}_{i}, \sigma_{-i} \mid h^{t}\right) \geq 0$.

\section{References}

[1] Brams, S. J., Davis, M. D. (1973). Resource allocation models in presidential campaigning: Implications for democratic representation. Annals of the New York Academy of Sciences, 219(1), 105-123. 
[2] Brams, S. J., Davis, M. D. (1974). The 3/2's rule in presidential campaigning. American Political Science Review, 68(1), 113-134.

[3] Deck, C., Sarangi, S., Wiser, M. (2017). Electoral College: A Multibattle Contest with Complementarities. Preprint.

[4] Dziubinski, M., Goyal, S., Minarsch, D. E. N. (2017). The Strategy of Conquest. https://doi.org/10.17863/CAM.7846

[5] Duffy, J., Matros, A. (2015). Stochastic asymmetric Blotto games: Some new results. Economics Letters, 134, 4-8.

[6] Fu, Q., Lu, J., Pan, Y. (2015). Team contests with multiple pairwise battles. The American Economic Review, 105(7), 2120-2140.

[7] Harris, C., Vickers, J. (1985). Patent races and the persistence of monopoly. The Journal of Industrial Economics, 33(4), 461-481.

[8] Kovenock, D., Roberson, B. (2009). Is the 50-state strategy optimal?. Journal of Theoretical Politics, 21(2), 213-236.

[9] Lake, M. (1979). A new campaign resource allocation model. In Applied Game Theory (pp. 118-132). Physica, Heidelberg.

[10] Sela, A., Erez, E. (2013). Dynamic contests with resource constraints. Social Choice and Welfare, 41(4), 863-882.

\section{Appendix}

\subsection{Example I}

The first order conditions of $v_{A}\left(\sigma \mid h^{1}\right)$ with respect to $\sigma_{A}^{2}\left(h^{1}\right)$ and $\sigma_{A}^{2}\left(h^{1}\right)$ are

$$
\begin{aligned}
\frac{\partial v_{A}\left(\sigma \mid h^{1}\right)}{\partial \sigma_{A}^{2}\left(h^{1}\right)} & =\frac{\partial v_{A}\left(\sigma \mid h^{1}\right)}{\partial w_{A}^{2}} \\
& =\frac{w_{B}^{2}\left(w_{B}^{1}+w_{B}^{2}-100\right)\left(w_{A}^{1}+2 w_{A}^{2}+w_{B}^{1}+2 w_{B}^{2}-200\right)}{\left(w_{A}^{2}+w_{B}^{2}\right)^{2}\left(w_{A}^{1}+w_{A}^{2}+w_{B}^{1}+w_{B}^{2}-200\right)^{2}}=0 .
\end{aligned}
$$




$$
\begin{aligned}
\frac{\partial v_{A}\left(\sigma \mid h^{1}\right)}{\partial \sigma_{B}^{2}\left(h^{1}\right)}= & \frac{\partial v_{A}\left(\sigma \mid h^{1}\right)}{\partial w_{B}^{2}} \\
= & -\frac{\left(w_{A}^{2}\right)^{2}\left(w_{B}^{1}+2\left(w_{B}^{2}-50\right)\right)}{\left(w_{A}^{2}+w_{B}^{2}\right)^{2}\left(w_{A}^{1}+w_{A}^{2}+w_{B}^{1}+w_{B}^{2}-200\right)^{2}} \\
& -\frac{w_{A}^{2}\left(w_{A}^{1}\left(w_{B}^{1}+2\left(w_{B}^{2}-50\right)\right)+\left(w_{B}^{1}\right)^{2}\right)}{\left(w_{A}^{2}+w_{B}^{2}\right)^{2}\left(w_{A}^{1}+w_{A}^{2}+w_{B}^{1}+w_{B}^{2}-200\right)^{2}} \\
& -\frac{w_{A}^{2}\left(2\left(w_{B}^{2}-150\right) w_{B}^{1}+2\left(w_{B}^{2}-100\right)^{2}\right)}{\left(w_{A}^{2}+w_{B}^{2}\right)^{2}\left(w_{A}^{1}+w_{A}^{2}+w_{B}^{1}+w_{B}^{2}-200\right)^{2}} \\
& -\frac{\left(w_{A}^{1}-100\right)\left(w_{B}^{2}\right)^{2}}{\left(w_{A}^{2}+w_{B}^{2}\right)^{2}\left(w_{A}^{1}+w_{A}^{2}+w_{B}^{1}+w_{B}^{2}-200\right)^{2}}=0 .
\end{aligned}
$$

From equations (4.6) and (4.7) we conclude best response functions $B R_{A}$ and $B R_{B}$ such that

$$
\begin{aligned}
B R_{A}\left(\sigma_{B}^{2}\left(h^{1}\right)\right)= & \frac{1}{2}\left(-w_{A}^{1}-w_{B}^{1}-2 w_{B}^{2}+200\right), \\
B R_{B}\left(\sigma_{A}^{2}\left(h^{1}\right)\right)= & \frac{-w_{A}^{2}\left(w_{A}^{1}+w_{A}^{2}+w_{B}^{1}-200\right)}{w_{A}^{1}+2\left(w_{A}^{2}-50\right)} \\
& +\frac{\sqrt{w_{A}^{2}\left(w_{A}^{1}+w_{A}^{2}-100\right)}}{w_{A}^{1}+2\left(w_{A}^{2}-50\right)} \\
& \times \frac{\sqrt{\left(w_{A}^{2}-w_{B}^{1}+100\right)\left(w_{A}^{1}+w_{A}^{2}+w_{B}^{1}-200\right)}}{w_{A}^{1}+2\left(w_{A}^{2}-50\right)} .
\end{aligned}
$$

The intersection of best responses provides us the following two conditions

$$
\begin{aligned}
& w_{A}^{2}=\frac{1}{2}\left(100-w_{A}^{1}\right), \\
& w_{B}^{2}=\frac{1}{2}\left(100-w_{B}^{1}\right) .
\end{aligned}
$$

The first order conditions of $v_{A}(\sigma)$ with respect to $\sigma_{A}^{1}(\varnothing)$ and $\sigma_{A}^{1}(\varnothing)$ are

$$
\begin{aligned}
\frac{\partial v_{A}(\sigma)}{\partial w_{A}^{1}}= & \frac{2\left(w_{B}^{1}-100\right)\left(w_{A}^{1}\right)^{2}\left(3 w_{B}^{1}-100\right)}{\left(w_{A}^{1}+w_{B}^{1}-200\right)^{3}\left(w_{A}^{1}+w_{B}^{1}\right)^{2}} \\
& +\frac{2\left(w_{B}^{1}-100\right)\left(w_{A}^{1} w_{B}^{1}\left(3 w_{B}^{1}-500\right)-200\left(w_{B}^{1}-100\right) w_{B}^{1}\right)}{\left(w_{A}^{1}+w_{B}^{1}-200\right)^{3}\left(w_{A}^{1}+w_{B}^{1}\right)^{2}}=0 \\
\frac{\partial v_{A}(\sigma)}{\partial w_{B}^{1}}=- & \frac{2\left(w_{A}^{1}-100\right)\left(\left(w_{A}^{1}\right)^{2}\left(3 w_{B}^{1}-200\right)\right)}{\left(w_{A}^{1}+w_{B}^{1}-200\right)^{3}\left(w_{A}^{1}+w_{B}^{1}\right)^{2}} \\
& -\frac{2\left(w_{A}^{1}-100\right) w_{A}^{1}\left(3\left(w_{B}^{1}\right)^{2}-500 w_{B}^{1}+20000\right)}{\left(w_{A}^{1}+w_{B}^{1}-200\right)^{3}\left(w_{A}^{1}+w_{B}^{1}\right)^{2}} \\
& +\frac{2\left(w_{A}^{1}-100\right)\left(100\left(w_{B}^{1}\right)^{2}\right)}{\left(w_{A}^{1}+w_{B}^{1}-200\right)^{3}\left(w_{A}^{1}+w_{B}^{1}\right)^{2}}=0 .
\end{aligned}
$$


From the above equations $\partial v_{A}(\sigma) / \partial w_{A}^{1}=0$ and $\partial v_{A}(\sigma) / \partial w_{B}^{1}=0$, we find the best response functions of player $A$ and $B$.

$$
\begin{aligned}
B R_{A}\left(\sigma_{B}^{1}(\varnothing)\right)= & \frac{-3\left(w_{B}^{1}\right)^{2}+500 w_{B}^{1}}{6 w_{B}^{1}-200} \\
& -\frac{\sqrt{9\left(w_{B}^{1}\right)^{3}-600\left(w_{B}^{1}\right)^{2}-70000 w_{B}^{1}+8000000} \sqrt{w_{B}^{1}}}{6 w_{B}^{1}-200} . \\
B R_{B}\left(\sigma_{A}^{1}(\varnothing)\right)= & \frac{-3\left(w_{A}^{1}\right)^{2}+500 w_{A}^{1}}{6 w_{A}^{1}-200} . \\
& -\frac{\sqrt{9\left(w_{A}^{1}\right)^{3}-600\left(w_{A}^{1}\right)^{2}-70000 w_{A}^{1}+8000000} \sqrt{w_{A}^{1}}}{6 w_{A}^{1}-200} .
\end{aligned}
$$

The intersection of the best responses leads to the condition $w_{A}^{1}=w_{B}^{1}=100 / 3$. 